\title{
Social Representation of Dementia: An Analysis of 5,792 Consecutive Cases Evaluated in a Memory Clinic
}

\author{
Pilar Cañabate ${ }^{\mathrm{a}, *}$, Gabriel Martínez ${ }^{\mathrm{a}, \mathrm{b}, \mathrm{c}}$, Maitée Rosende-Roca ${ }^{\mathrm{a}}$, Mariola Moreno ${ }^{\mathrm{a}}$, Silvia Preckler ${ }^{\mathrm{a}}$, \\ Sergi Valero ${ }^{\mathrm{a}, \mathrm{d}}$, Oscar Sotolongo ${ }^{\mathrm{a}}$, Isabel Hernández ${ }^{\mathrm{a}}$, Montserrat Alegret ${ }^{\mathrm{a}}$, Gemma Ortega $^{\mathrm{a}}$, \\ Ana Espinosa ${ }^{\mathrm{a}}$, Ana Mauleón ${ }^{\mathrm{a}}$, Liliana Vargas ${ }^{\mathrm{a}}$, Octavio Rodríguez ${ }^{\mathrm{a}}$, Carla Abdelnour ${ }^{\mathrm{a}}$, \\ Domingo Sánchez $^{\mathrm{a}}$, Elvira Martín ${ }^{\mathrm{a}}$, Agustín Ruiz ${ }^{\mathrm{a}}$, Lluís Tárraga ${ }^{\mathrm{a}}$ and Mercè Boada ${ }^{\mathrm{a}}$ \\ ${ }^{\mathrm{a}}$ Memory Clinic and Research Center of Fundació ACE. Institut Català de Neurociènces Aplicades, \\ Barcelona, Spain \\ ${ }^{\mathrm{b}}$ Iberoamerican Cochrane Centre, Barcelona, Spain \\ ${ }^{\mathrm{c}}$ Faculty of Medicine and Dentistry, University of Antofagasta, Antofagasta, Chile \\ ${ }^{\mathrm{d}}$ Department of Psychiatry, Hospital Universitari Vall d'Hebron, CIBERSAM, Universitat Autònoma de \\ Barcelona, Barcelona, Spain
}

Accepted 5 April 2017

\begin{abstract}
.
Background: Different interpretations of cognitive impairment and dementia due to differences in health structures, such as cultural differences could affect the diagnosis and treatment of the condition. it is reasonable to expect that the social and family impact of the disease and coping strategies will differ among societies.

Objective: The general aim of this study is to understand the social representations of dementia, its associated practices, and the effects they imply.

Methods: People diagnosed with clinical dementia and their families were assessed from 2005 to 2015 in the memory clinic of the Fundació ACE, Institut Català de Neurociències Aplicades in Barcelona, Spain.

Results: 9,898 people were examined and 5,792 were diagnosed with dementia. For those with a caregiver (71\%), the decision-making fell on the person with dementia in $16.2 \%$ of the cases; and for those without a caregiver, in $26.4 \%$ of the cases the family did not perceive the deficits as a disease, which led to multiple risk situations (74.6\%).

Conclusions: The recognition of dementia as part of aging is common among families. Consequently, risk situations may arise and diagnosis and access to treatment may be delayed. The incorporation of a social appraisal to the diagnostic process is a necessity to evaluate these situations.
\end{abstract}

Keywords: Alzheimer's disease, beliefs, caregiver, dementia, social perception, social representation, social-cultural

\footnotetext{
*Correspondence to: Pilar Cañabate, PhD, Fundació ACE, Institut Català de Neurociències Aplicades, Gran Vía Carles III, 85 bis, Barcelona, Spain. Tel.: +34 934 304720; Fax: +34 934101 701; E-mail: pcanyabate@fundacioace.com.
}

\section{INTRODUCTION}

The aging population is a worldwide reality. In 2015 , approximately $12.2 \%$ of the world population was older than 60 years, and it is expected to grow up to $21.2 \%$ by 2050 [1]. In Spain, it is estimated that the age group over 60 years will constitute $43 \%$ 
of the population by 2050 [2]. The aging population has prompted an increase in the incidence of multiple chronic diseases, including dementia syndrome, affecting public pension programs, healthcare and social assistance, and implying an obvious economic impact on Western countries [3].

Currently, around 46.8 million people worldwide have dementia. This number is expected to reach 131.5 million by 2050 [1]. In Spain, the current prevalence of dementia ranges from 5 to $14.9 \%$ for people over 65 years of age and from 6.6 to $17.2 \%$ for those over 70 [4]. Nowadays, everything indicates that the cost of the disease will rise even faster than its prevalence itself [1]. Dementia syndrome has many different causes, with Alzheimer's disease (AD) the most important. In Catalonia, Spain, AD affects almost $70 \%$ of the people diagnosed with dementia, and the prevalence is $6.6 \%$ for those of 70 years of age or older, reaching almost $32 \%$ for the age group 90 to 95 [5].

Dementia, regardless of its cause, can be used as a model to understand families' behaviors within every culture, and how different health service frameworks pinpoint what is health and what is illness, as well as the practices related to these categories. Papers about dementia's social aspects become more frequent; the majority of them are, however focused on American, Anglo-Saxon, and North European realities. Human and social sciences have shown that there is a lack of research on caregivers and their experience with dementia and its impact on other societies with different social and health structures, as well as other ways of understanding cognitive impairment [6-11]. Therefore, due to differences in health structures, such as cultural differences (conception of and meaning given to the manifestations of dementia, differences between family and social values, differences in approaches for caregiving), it is reasonable to expect that the social and family impact of the disease and coping strategies will differ among societies.

Based on the aforementioned information, this research attempts to disclose the particular reality in Catalonia, specifically in Barcelona. The general aim of this study is to understand the social representations of dementia, its associated practices, and the effects they imply. Thus, we studied clinical and social situations in which the person with dementia presents at a memory clinic for a first evaluation. We have looked at the individual's clinical conditions (cognitive status, dependence, and behavior); sociodemographic characteristics of their social and family environment; representations they have about cognitive impairment and care structure characteristics, and effects-both on the caregiver and the caretaker-at the very moment the person is diagnosed with cognitive impairment.

\section{METHODS}

\section{Geographic reference area}

The study geographic area is Barcelona city, with an average population of around 1,600,000, of whom $18.5 \%$ are over 65 years old [12].

\section{Data collection center}

The study data were collected in the Memory Clinic of the Fundació ACE, Institut Català de Neurociències Aplicades, a non-profit organization, and their service area is the city of Barcelona. The Memory Clinic has a contract by a public bidding process since June 22nd, 2012 with the Servei Català de la Salut del Departament de Salut de la Generalitat de Catalunya. People were referred to the center by Primary care physician or specialists due to persistent memory complaints (or other cognitive impairment), perceived by themselves, their families or medical doctor.

Diagnosis was done systematically and following a protocol to collect as much information as possible. In this process, a professional expert in social evaluations made the first visit with the family, presented the service, explored the reason for consultation, and carried out a detailed social and family study to place the evaluated person within their social context (Supplementary Figure 1). A neurologist had a second visit with the family and the evaluated person for anamnesis and neurological examination. Thirdly and finally, a neuropsychologist completed the study with an extensive evaluation of the person's cognitive functions and with additional tests (lab test and neuroimaging) required by the neurologist. When all data were available, the diagnosis and plan of action, including the management of the person and their family or caregiver, were carried out by consensus of the entire team of the diagnostic unit $[13,14]$ (Supplementary Figure 2).

Clinical and social data obtained after diagnosis have been collected and systematized since 1996 and were recorded in the computerized database created ad hoc to configure the medical history of the subject.

Written informed consent was obtained for all participants. In order to maintain confidentiality, all 
participants' details were anonymized in the transcripts of the interviews.

\section{General aspects of the methodology}

The analysis was done studying the medical records of people evaluated in the memory clinic. We presented data of people diagnosed with dementia in particular, according to the diagnostic criteria DSMIV-TR [15] and DSM V [16] in the Fundació ACE from 2006 to 2015.

The diagnostic criteria used to classify the etiology of dementia were: for AD, the National Institute of Neurologic, Communicative Disorders and Stroke Alzheimer's Disease and Related Disorders Association criteria (NINCDS-ADRA) [17]; and the National Institute on Aging - Alzheimer Association criteria (NIA-AA) [18]; for the diagnosis of vascular dementia, the National Institute of Neurological Disorder and Stroke and Association Internationale pour la recherche et l'Enseignement in Neurosciences criteria (NINDS-AIREN) [19]; the Neary et al. [20] for the diagnosis of frontotemporal dementia; McKeith criteria et al. [21] for Lewy body dementia.

We conducted a descriptive and observational study to achieve the abovementioned objectives, a strategy that combined the qualitative and quantitative perspectives.

Quantitative perspectives included the exploitation and analysis of the information in the medical record. The qualitative analysis was performed based on the analysis of data recorded in the notes, systematically collected by the professional expert in social evaluations in interviews. These data are mainly an extension of information that helps understand the quantitative data.

\section{Terminological definitions}

In this study, we presented terms that were used by specialists and the general population with different meanings and nuances.

We used "care" as a purpose rather than a task. Therefore, we consider a caregiver to be the person that takes decisions about the needs of the patient and about how these needs could be met, regardless of whether this person actually carries out the tasks or not. In this study, we have started from the premise that there is no direct relationship between being a caregiver and living with the person with dementia. Hence, in situations where the dementia patient lived with a relative, if this relative did not carry out care-related tasks (consciously or not), we did not consider the relative as a caregiver. On the other hand, if an assistant was contracted by a relative to take direct care of the patient, we did consider the relative-who took responsibility for managing and deciding on the patient's care-as a caregiver.

Representations consisted of information, images, beliefs, values, opinions, cultural, and ideological elements that will guide the action, or non-action, of the subjects [22]. Disease representations are based on cognitive rules and regulations that are used to interpret our experience of the disease. These rules are deeply rooted and become tacit [23]. Changes in representations can be a long-term process; hence, we could find discrepancies and conflicting uses of certain terms and concepts.

"Impact" is a concept that we used to value the emotional and social consequences of caregiving, such as disturbance in family relationships, and in occupational, leisure, and economic activities [24].

We used the concept of "role restructuring/reorganization" for the delegating of responsibilities and functions to another person as a consequence of cognitive impairment of dementia, which provokes a decreasing ability of the subject to perform functions and take on responsibilities.

\section{Characterization of the relevant variables in the study}

Variables analyzed in this study were divided into three blocks and are as follows:

a) Sociodemographic variables of the patient: age, sex, education, marital status, the person or people they live with, occupation, etc.

b) Diagnosis: etiological diagnosis, degree of cognitive and physical autonomy (according to the scores in the Mini-Mental State Examination (MMSE) [25], Blessed Dementia Rating Scale [26], Rapid Disability Rating Scale-2 [27] and Global Deterioration Scale (GDS) [28]).

c) Interpretations on the cognitive impairment: Knowledge about dementia, how the impairer's situation is understood, on-setting of therapeutic pathway.

d) Features/particularities/details of the care structure: existence of a caregiver, caregiver's gender, family relationship with the subject, way in which the role of caregiver was assumed, caregiver activity and impact on caregiver's 
life expectations care strategies, people without caregiver and their reality, existence of risk.

\section{Data analysis}

A descriptive analysis of the variables was performed using frequency analysis and measures of central tendency and dispersion for quantitative variables. Results were expressed as absolute numbers, percentages, mean and standard deviation.

Data processing and analysis were conducted using SPSS statistical software v. 19.0, Chi-square test was used to compare the variables. Alpha level was set at 0.05 .

Qualitative data from clinical records were checked. These data were codified into category labels, and were then ordered into groups. Data were analyzed and compared; first within each category, and then between categories. The goal was to find links between them. To do such analysis, latent contents and context were taken into account.

The statement of the informants has been transcribed verbatim. These transcriptions have been filed separately from the text and in quotation marks.

\section{RESULTS}

We evaluated 9,898 people from January 2006 to July 2015; all of them received social and family assessment as part of a comprehensive process of diagnosis. $67.5 \%$ were women, mean age was 77.3 $(\mathrm{SD}=8.9)$. Of all people evaluated, 5,840 (59\%) had dementia syndrome, 3,335 (33.7\%) mild cognitive impairment, and 723 (7.3\%) no cognitive impairment.

Current data presented in this article correspond to 5,792 people who were diagnosed with dementia syndrome, 48 cases were excluded because data were not available.

Diagnostic and sociodemographic characteristics are presented in Table 1.

\section{Representations of dementia}

Regarding social representations of dementia, our study found inconsistencies in terminological and conceptual aspects of the term "dementia". Many people considered cognitive impairment produced by dementia as a natural fact in the elderly, and a part of the aging process, but it is not considered as a disease. The recognition of dementia as a part of the aging process promoted an acceptation of the symptoms and a
Table 1

Diagnostic and sociodemographic characteristics

\begin{tabular}{|c|c|}
\hline Dementia patients $n(\%)$ & $5,792(58.5)$ \\
\hline Age (mean/SD) & $79.9( \pm 7.7)$ \\
\hline \multicolumn{2}{|l|}{ Gender $n(\%)$} \\
\hline Male & $1,739(30)$ \\
\hline Female & $4,053(70)$ \\
\hline \multicolumn{2}{|l|}{ Education $n(\%)$} \\
\hline$<6$ years & $3,018(52.1)$ \\
\hline Primary & $1,743(30.1)$ \\
\hline Secondary & $631(10.9)$ \\
\hline University & $400(6.9)$ \\
\hline \multirow{2}{*}{\multicolumn{2}{|c|}{$\begin{array}{l}\text { Marital Status } \\
\text { female }(\%) / \text { male } \%\end{array}$}} \\
\hline & \\
\hline Married/couple & $36.5 / 77.9$ \\
\hline Divorced & $2.9 / 2.8$ \\
\hline Single & $6.7 / 4.4$ \\
\hline Widow(er) & $53.9 / 14.8$ \\
\hline \multicolumn{2}{|l|}{$n(\%)$ of patients living } \\
\hline In a Couple & $2,473(42.7)$ \\
\hline Alone & $1,355(23.4)$ \\
\hline With Son or daughter & $655(11.3)$ \\
\hline $\begin{array}{l}\text { In a nursing home or with } \\
\text { professional caregiver }\end{array}$ & $319(5.5)$ \\
\hline Other & $990(17.1)$ \\
\hline \multicolumn{2}{|l|}{ Types of dementia $n(\%)$} \\
\hline Alzheimer's disease & $4,102(70.8)$ \\
\hline Vascular dementia & $770(13.3)$ \\
\hline Lewy body dementia & $439(7.6)$ \\
\hline Frontotemporal dementia & $280(4.8)$ \\
\hline Other & $201(3.5)$ \\
\hline \multicolumn{2}{|l|}{$\operatorname{MMSE} n(\%)$} \\
\hline MMSE $>20$ & $3,011(52)$ \\
\hline MMSE 10-20 & $2,491(43)$ \\
\hline MMSE $<10$ & $290(5)$ \\
\hline \multicolumn{2}{|l|}{ Global Deterioration Scale $n(\%)$} \\
\hline Mild dementia (GDS 4) & $3,469(59.9)$ \\
\hline Moderate dementia (GDS 5) & $1,830(31.6)$ \\
\hline Mod-severe dementia (GDS 6) & $452(7.8)$ \\
\hline Severe dementia (GDS 7) & $41(0.7)$ \\
\hline \multicolumn{2}{|l|}{ RDRS-2 (mean SD) } \\
\hline Activities of daily living & $13.5( \pm 4.6)$ \\
\hline Degree of disability & $12.1( \pm 2.3)$ \\
\hline Special problems & $5.3( \pm 1.1)$ \\
\hline \multicolumn{2}{|l|}{ Blessed (mean SD) } \\
\hline $\begin{array}{l}\text { Changes in performance of everyday } \\
\text { activities }\end{array}$ & $3.66( \pm 1.4)$ \\
\hline Changes in habits & $1.63( \pm 1.8)$ \\
\hline Changes in personality, interests, drive & $3.15( \pm 1.3)$ \\
\hline
\end{tabular}

less negative association, despite being considered as a disease in the medical discourse.

While the medical narrative uses the word "dementia" to point out a symptom associated to a pathology, for most ordinary people the word "senile dementia" refers to quite a normal, common and frequent agerelated situation and not at all pathological. It is, in a way, as if abnormality has somehow been normalized.

"Dementia yes, but she is not sick."

"He has dementia, but he is in good health." 
"He is in good health, he is just senile."

"He has age-related dementia."

"He should have something at his age, right? I do not know what the doctor expected! He is 80 years old!"

Unlike what happens with senile dementia, lay people consider the word 'Alzheimer's' as a paradigm of dementia, and is always linked to the pathological realm. Mentioning the word itself is a cause of distress:

"It's the worst you can go through because it is against every logic. It is a monstrosity, something incomprehensible [...]. Alzheimer is destructive, as it completely impairs the sufferer."

'I have a really bad image of Alzheimer's. That's the reason I got scared... To me, Alzheimer's is being dead and alive simultaneously."

While within the clinical practice there is an evolutionary criterion from lower to higher degree of impairment, ordinary people identify Alzheimer's when there is a moderate or advanced stage, but not when it is mild. A mild or low intensity of impairment is seen by lay people as something normal, and it is labelled as "senile dementia". However, when the intensity of dementia peaks, the term shifts to "Alzheimer's":

"He has a bit of Alzheimer's but not completely"

"He has suffered senile dementia for 10 years, but now he has developed Alzheimer's, because when he wakes up he is unable to put his slippers on. He doesn't remember that dad died... within a minute he has forgotten everything. He is never hungry, and I have to nudge him to wake him up. That's why I say that he has stridden from dementia to Alzheimer's."
“She hasn't got Alzheimer's, she's got a senile dementia according to her age. She still recognizes me."

"My grandma's got a normal senile dementia. It has nothing to do with my mother's Alzheimer' s."

"Someone with Alzheimer's is a kind of living dead. They don't know where they are. "She's not like that; she's got a senile dementia."

\section{Access to the diagnostic process}

For $79.6 \%$ of all people diagnosed with dementia, access to the diagnostic process was promoted by the family; for $1.8 \%$ by the affected itself; and for $18.6 \%$ by a medical professional. These proportions vary according to the disease status measured by MMSE and GDS. We found a statistically significant difference in the patient's stage of dementia, depending on who started the diagnostic process. When the process was triggered by a relative or healthcare practitioner, $32.3 \%$ or $30.9 \%$ of the individuals with dementia were in a moderate stage and $7.7 \%$ or $8.1 \%$ were in a moderately severe stage, respectively, whereas when it was the patient itself, dementia was in a mild stage in $86.4 \%$ of the cases and in a moderate or moderately severe stage in $13.6 \%$ of the cases $(p=0.03)$ (Table 2).

When it was the clinician who had initiated the diagnostic process, the relatives of the patient either did not observe any alteration in the patient's normal state or did not place importance to any deficiencies; they attributed them to the person's age or mood, rather than to a disease:

"He has better memory than myself, he even remembers when he was a child... I do not know why the doctor says that he is losing his memory".

"If she is not well, she would have told us ... she has not said anything".

Table 2

Cognition, disease status, and access to diagnostic process

\begin{tabular}{|c|c|c|c|c|c|c|c|c|c|}
\hline \multirow{2}{*}{$\begin{array}{l}\text { Scale } \\
\text { Range }\end{array}$} & \multirow[b]{2}{*}{$26-30$} & \multicolumn{3}{|c|}{ MMSE } & \multirow[b]{2}{*}{$0-9$} & \multicolumn{4}{|c|}{ GDS } \\
\hline & & $20-25$ & $15-19$ & $10-14$ & & 4 & 5 & 6 & 7 \\
\hline \multicolumn{10}{|c|}{ Access to diagnostic process } \\
\hline \multicolumn{10}{|l|}{ Family } \\
\hline $79.6 \%$ & $8.7 \%$ & $43.2 \%$ & $31.4 \%$ & $11.7 \%$ & $5 \%$ & $59.5 \%$ & $32.3 \%$ & $7.7 \%$ & $0.5 \%$ \\
\hline \multicolumn{10}{|c|}{ Evaluated person } \\
\hline $1.8 \%$ & $14.6 \%$ & $63.1 \%$ & $15.5 \%$ & $6.8 \%$ & $0 \%$ & $86.4 \%$ & $11.7 \%$ & $1.9 \%$ & $0 \%$ \\
\hline \multicolumn{10}{|c|}{ Medical doctor } \\
\hline $18.6 \%$ & $7.9 \%$ & $42.5 \%$ & $32.5 \%$ & $12.2 \%$ & $4.9 \%$ & $60 \%$ & $30.9 \%$ & $8.1 \%$ & $0.9 \%$ \\
\hline
\end{tabular}

MMSE, Mini-Mental State Examination; GDS, Global Deterioration Scale. 
"What happens is that she does not remember knowing. She is not unsound".

"It's normal, she is getting older".

"She dodders, but she is not sick; it is because of her age."

"She has memory, she just forgets things."

\section{The caregiver}

A total of $4,110(71 \%)$ of people diagnosed with dementia had a caregiver at their disposal; caregivers were relatives in $82.5 \%$ of the cases. Of these, in $52.8 \%$ of the situations the caregiver role was performed by one person alone, and was shared among different members of the family in $28.5 \%$. Only $1 \%$ of the non-outsourced caregivers were not relatives. In $16.3 \%$ of the cases, the caregiver was outsourced (in-home or nursing home caregiver).

\section{Caregiver characteristics}

Primary caregivers were women in $67.2 \%$ of the cases. In $32.4 \%$, it was the wife, followed by daughters in $27.6 \%$ of the cases. The husband in $22.3 \%$ of the cases, sons in $9.1 \%$, and in $8.6 \%$ primary caregiving was provided by a very heterogeneous group of relatives (nephews, brothers, etc.) and professional caregivers.

Impact on the caregiver's life expectations and the way in which the role was assumed

Caregiving was in confrontation with the caregiver's life expectations in $14.5 \%$ of the cases $(n=595)$, and, it was in line with their expectations in $85.5 \%$ of the cases. The reasons stated were:

- Moral obligation in $48.8 \%$ :

"I married for better and for worse"

"Who else but a son!"

"She did it for me, so she will be at home with me."

- Domestic task in 2.3\%:

"He does not cause me any trouble. If the ill had been me, it would have been a problem because he has never done anything at home."
"It has always been me who has taken care of home matters. I took care of my parents, his parents, our children; this is not new to me."

\section{- Domestic task and moral obligation in $34.5 \%$}

The caregiver role was assumed slowly and progressively over time in $73.1 \%$ of the situations. In addition, in $26.9 \%$ of the cases the role was abruptly started at a time of crisis. In relation to gender, women took on the caregiver role abruptly in $22.4 \%$ of the cases and in $15 \%$ for men $(p<0.001)$.

The caregiver's work, couple relationship, and/or leisure was adversely affected for $10.4 \%$ of those who assumed caregiving responsibilities slowly and for $27.8 \%$ of those who did it abruptly:

"I've had to retire early to take care of her."

"I have not had vacations in three years. I'm tired."

"I have received a warning at my job; I cannot take so many days off to accompany him to the doctor."

"I cannot see my grandchildren because she has it in for them, gets angry and yells at them."

The caregiver was overwhelmed ("I can't take it anymore") in $26.3 \%$ of the situations:

"I cannot do this for much longer."

"On Sundays, I want it to be Monday to go to work and leave the house."

"Either something's done or we will both be hospitalized."

We found significant differences regarding the caregiver gender and his/her self-perceived overwhelm: $30.9 \%$ of the female caregivers were overwhelmed compared to $23.6 \%$ of the male caregivers $(p<0.001)$

When the care structure and caregiver were decided upon previously, the caregivers were relatives in $63.1 \%$ of the cases: $42.6 \%$ were women, $20.5 \%$ were men.

In $36.9 \%$ of the cases, other forms of care (in-home care service, daycare center or nursing home) were planned.

When neither the care structure nor caregiver were decided upon previously, $34.9 \%$ of caregivers were relatives: $23 \%$ were women, $11.9 \%$ men, and in 
Table 3

No caregiver: frequency, status of dementia, and gender

\begin{tabular}{lccl}
\hline GDS & Frequency & No Caregiver & Gender \\
\hline GDS 4 & $59.9 \%$ & $81.7 \%$ & Female 71.8\% \\
& & $n=1,374$ & Male 28.2\% \\
GDS5 & $31.6 \%$ & $16.8 \%$ & Female 78.1\% \\
& & $n=283$ & Male 21.9\% \\
GDS 6 & $7.8 \%$ & $1.5 \%$ & Female 80\% \\
& & $n=25$ & Male 20\% \\
\hline
\end{tabular}

*All GDS-7 had a caregiver.

$65.1 \%$ of the cases they were other forms of care (inhome care service, daycare center or nursing home).

\section{People with dementia without caregivers}

No caregiver was at the disposal of $29 \%(n=1,682)$ of the people with dementia. From these, $81.7 \%$ $(n=1376)$ were GDS-4 and $16.8 \%(n=283)$ were GDS-5.

In those individuals with dementia with no caregivers, $73 \%$ of them were women and $27 \%$ were men. The frequency, status of dementia, and gender are shown in Table 3.

A total of $37.5 \%(n=637)$ of people without caregiver were living alone; nonetheless, the lack of caregiver was unrelated to whether the individual was living alone or with other people. Thus, $43.9 \%$ lived with their partner, $6.6 \%$ lived with a son or daughter, $11 \%$ lived with other relatives, and $0.9 \%$ lived in a nursing home or a relative (no person responsible for decision-making was identified).

The lack of caregiver for those living alone was neither related to the type of family relationship. In $80.6 \%$ of cases, relations with relatives were good, while in $7.3 \%$ of cases, relations were conflictive, and in $6.8 \%$ were undifferentiated. Only in $5.3 \%$ of cases, the individual with dementia living alone had no family. Data showed that in $21.6 \%$ of the cases in which individuals with dementia were living alone and without caregiver, their relatives did not think they were ill.

\section{Interpretation of cognitive impairment when} there is no caregiver

In $24.6 \%$ of all situations in which there was no caregiver, the family did not perceive that the person was ill. In the remaining $75.4 \%$ - even though the family interpreted cognitive deficits of their relative as a result of a disease, relatives stated various reasons to argue their interpretation of the symptoms. a) Waiting for clinical diagnosis to take action

"She has always been very manipulative and now we are not sure if she is tricking us and we have to force her, or if she really cannot do things."

"I'm waiting for the verdict; we'll see what I do."

b) They do not know how to tell the patient

"I do not know how to tell her that she needs our help."

"I do not know what I have to do or what's best for him."

c) Patient does not accept supervision

"She does not accept help."

"We cannot say to her that she cannot be alone; she does not accept it."

"He does not want us to watch him."

"If we go there, she shouts and accuses us of stealing. Now we do not go there anymore."

d) Potential caregiver does not want to take care of the patient

"She has always been very selfish and has not cared about anyone. It's very hard to say, but I'm not going to take care of her... she gave us a very bad life."

\section{"These people are better in a nursing home."}

"I cannot take care of her in my house; she must go to a nursing home."

\section{Impacts}

Risk situations in care of the dementia person

In assessing risk situations in patient's care, the study found that care was guaranteed in $25.4 \%$ of the cases. However, care was not ensured for $74.6 \%$ of the patients due to existing risk.

Among the risks identified, the experts noted: $19.8 \%$ of the caregivers worked alone; $18 \%$ of the caregivers felt overwhelmed; $22.7 \%$ of the people with dementia had no caregiver; $11.6 \%$ of the families did not believe that their relative was sick. 
The specialist noted further risks in care in $2.5 \%$ of the patients (lack of support, caregiver emotional distress, etc.).

Driving was also considered an unsafe situation. It was found that $5.6 \%(n=322)$ of the people diagnosed with dementia were drivers. $89.1 \%$ of them had a GDS-4 and $10.9 \%$ GDS-5. In relation to gender, $80.7 \%$ were men.

\section{Decision making}

In those with a caregiver, the decision making still fell on the person with dementia in $16.2 \%(n=666)$ of the cases. Furthermore, $79.5 \%$ of them were in a phase of mild dementia (GDS-4) and $18.5 \%$ of moderate dementia (GDS-5).

\section{DISCUSSION}

To the best of our knowledge, this is the first study that has evaluated the social representations of dementia and the structure of care at the moment of diagnosis.

The aim of this study was to describe the views of the Catalan population about dementia and practices associated with its representations. We started from the premise that social representations of dementia determine specific actions: the timing for evaluation in a memory clinic, the patient's needs and how these will be addressed.

Therefore, in this study, we examined and analyzed the cognitive status and autonomy of the person with dementia on the one hand, and characteristics of the care structure, representations of the situation within their social and family environment, and their consequences evaluated by a professional expert in social evaluations.

We combined quantitative and qualitative methodology. The quantitative approach has allowed us to evaluate manifestations of dementia, and the qualitative approach has helped us understand the logic behind the caregiver's attitudes, the meaning they give to the symptoms of dementia, and discover the aspects involved in the care structure.

Although in Spain there are no studies with a sample as large as ours, the results about demographic data both from the individual with dementia and from the caregiver obtained in the city of Madrid [29], Pamplona [30], the province of Gerona [31], the region of Baix Llobregat [32], or the results gathered in the Guide of the Clinical Practice [33] are similar to ours. That is the reason why we consider that our results also represent Spain as a whole.

The timing of information collection (at the moment of diagnosis of the disease), as well as some of the studied variables (the interpretation given by the informants about behavior, cognitive deficiencies, or how the subjects' care structure was planned) represent new data, and could not be generalizable to other cultures or countries, because previous studies were mainly focused on caregiver interviews after a period of time since the diagnosis of dementia [6-11].

Such interpretation of cognitive impairment explains $11.6 \%$ of the situations in which relatives of a person diagnosed with dementia did not identify the clinical status as a consequence of a disease; they, therefore, did not expect such clinical diagnosis. This could in some extent explain why the diagnosis of dementia in almost four out of ten individuals was done in a moderate or severe stage of the disease and not at earlier stages. The latter could also cause a delay in diagnosis, affecting the access to an appropriate treatment and intervention for the patient, and a delay in all those interventions focused on relatives to prevent and treat caregiver stress.

Even with the correct identification of the syndrome's manifestations, we found difficulties in recognizing complications and repercussions of these deficits on daily life and on the suitable care. Hence, we have been able to identify several risk situations in people who have been diagnosed with dementia in our environment: $23.4 \%$ of people diagnosed with dementia live alone, $6.6 \%$ drive, $29.3 \%$ are under nobody's supervision, and $37.7 \%$ make major decisions.

Our work establishes the "feminization of dementia"; up to $70 \%(n=4,022)$ of individuals diagnosed with dementia are women. But that is not the only reason. Regardless of the gender of the individual with dementia, the role of the caregiver-even when there was no clear decision on who would take the role prior to diagnose-was eventually assumed by a woman.

For most of them, women take up this chore according to a naturalization of the role, to which affect and a moral dimension, commonly associated with family duties, add up. Other aspects also contribute to this feminization, like a maternal-role extension, the regular association between chores and genders, or the diverse dynamics arising within a family and shaped by gender. 
The resulting impact and burden are directly related to how this responsibility was assumed and to a good attitude in advance to taking up this role.

Thus, both in the situations when the person assuming the role of caregiver was decided beforehand and when the prospective caregiver took up this role smoothly, the impact and the burden were less compared to when the role of the caregiver was not previously assigned and accepted, or to when it was abruptly assumed without a chance of realizing what it meant in the intermediate and long term.

\section{Conclusion}

The results presented here are an approximation to the situation at the moment of diagnosis made by a social evaluation, which gave us a more comprehensive assessment of people with dementia and the structure of care. This evaluation has been essential to understand the perception of the population regarding the syndrome, and the logic and sense behind the practices related to it.

In this study, we observed how the population found difficult to interpret the syndrome: they do not consider it as a disease and have problems understanding the needs of the patient and helping to address them. Changing this situation requires a previous modification of the representation associated to dementia. If the representation remains unchanged, we will not be able to modify risk practices.

As for now, on the one hand, our interest is to conduct a longitudinal analysis of these cases, in order to analyze whether and how the diagnosis of dementia triggers or not a change in the representations of the disease in those involved and in the care plan. On the other hand, we intend to make a multicenter and international study to learn the representations of dementia at the moment of diagnosis in different countries and cultures.

Including a social assessment in the diagnosis will allow us to study practices and social representations, allowing the development of strategies to recognize and prevent risk situations. This could favor an early diagnosis and the elimination of risk factors for the person with dementia and their caregiver. Additionally, this might change the human resources requirements in memory clinics and the promotion of activities for the early diagnosis of dementia by policy makers.

\section{ACKNOWLEDGMENTS}

We express our gratitude to all the patients and their relatives who participated in or supported this research.

This research did not receive any specific grant from funding agencies in the public, commercial, or not-for-profit sector. This study has been funded by Fundació ACE's own research funds.

Gabriel Martínez is a PhD candidate in Methodology of Biomedical Research and Public Health at the Department of Paediatrics, Obstetrics and Gynaecology and Preventive Medicine, Universitat Autònoma de Barcelona, Barcelona, Spain.

Authors' disclosures available online (http://j-alz. com/manuscript-disclosures/16-1119r3).

\section{SUPPLEMENTARY MATERIAL}

The supplementary material is available in the electronic version of this article: http://dx.doi.org/ 10.3233/JAD-161119.

\section{REFERENCES}

[1] World Alzheimer Report 2015, The Global Impact of Dementia, An analysis of prevalence, incidence, cost and trends, Alzheimer's Disease International, 2015, http:// www.alz.co.uk/research/WorldAlzheimerReport2015.pdf, Last updated October, 2015, Accessed on May 2, 2016.

[2] Instituto Nacional de Estadísticas, INE, Spain, 2014. http:// www.ine.es/jaxi/Datos.htm?path=/t20/p278/p01/serie/10/\& file $=01001$.px\&type $=$ pcaxis, Last updated October 28 , 2014, Accessed on May 2, 2016.

[3] World report on ageing and health, WHO, 2015. http:// apps.who.int/iris/bitstream/10665/186463/1/978924069481 1_eng.pdf?ua=1, Last updated September 30, 2015, Accessed on May 2, 2016.

[4] de Pedro-Cuesta J, Virués-Ortega J, Vega S, Seijo-Martínez M, Saz P, Rodríguez F, Rodríguez-Laso A, Reñé R, Pérez de las Heras S, Mateos R, Martínez-Martín P, Manubens JM, Mahillo-Fernandez I, López-Pousa S, Lobo A, Llinàs Reglà J, Gascón J, García FJ, Fernández-Martínez M, Boix R, Bermejo-Pareja F, Bergareche A, Benito-León J, de Arce A, del Barrio JL (2009) Prevalence of dementia and major dementia subtypes in Spanish populations: A reanalysis of dementia prevalence surveys, 1990-2008. BMC Neurology 9, 55 .

[5] GENCAT 2009, Pla de salut de Catalunya a l'horitzó 2010: Informe de salut a Catalunya. http://salutweb.gencat. cat/web/.content/home/ambits_tematics/linies_dactuacio/sa lut_i_qualitat/pla_salut_catalunya/pla_de_salut_de_catalunya _a_lhoritzo_2010/informe_de_salut_a_catalunya_avaluacio_d els_objectius_de_salut/mes_informacio/0_pla_de_salut_de_c atalunya_a_horitzo_2010_2apart_tot.pdf, Last updated March, 2009, Accessed on May 2, 2016.

[6] Fox K, Hinton WL, Levkoff S (1999) Take up the caregiver's burden: Stories of care for urban African American elders with dementia. Cult Med Psychiatry 4, 501-529. 
[7] Faure-Delage A, Mouanga AM, M'belesso P, Tabo A, Bandzouzi B, Dubreuil CM, Preux PM, Clément JP, Nubukpo $P$ (2012) Socio-cultural perceptions and representations of dementia in Brazzaville, Republic of Congo: The EDAC Survey. Dement Geriatr Cogn Disord 2, 84-96.

[8] Juarez-Cedillo T, Jarillo-Soto EC, Rosas-Carrasco O (2014) Social representations of dementia and its influence on the search for early care by family member caregivers. Am $J$ Alzheimers Dis Other Demen 29, 344-353.

[9] Lo Sterzo E, Orgeta V (2015) Illness representation and sense of coherence in dementia caregiving. J Health Psychol, doi: 10.1177-1359105315613132. [Epub ahead of print]

[10] Quinn C, Jones IR, Clare L, Zeiling H (2016) Illness representations in caregivers of people with dementia. Aging Ment Health 5, 1-9.

[11] Clare L, Quinn C, Jones IR, Woods RT (2016) “I don't think of it as illness": Illness representations in mild to moderate dementia. J Alzheimers Dis 51, 139-150.

[12] IDESCAT, Instituto de Estadística de Cataluña, http://www. idescat.cat/pub/?id=aec\&n=254\&lang=es, Accessed on April 7, 2016.

[13] Boada-Rovira M (1998) El papel de las unidades de diagnóstico y evaluación de los trastornos cognitivos y de la conducta ante el diagnóstico precoz de la enfermedad de Alzheimer. Análisis de 962 casos consecutivos, período 1996-1997 Fundación ACE. Rev Neurol 27(Supl 1), S5-S15.

[14] Boada M, Tárraga L, Hernández I, Valero S, Alegret M, Ruiz A, Lopez OL, Becker JT, Fundació ACE, Alzheimer Research Center, Memory, Clinic (2014) Design of a comprehensive Alzheimer's disease clinic and research center in Spain to meet critical patient and family needs. Alzheimers Dement 10, 409-415.

[15] American Psychiatric Association (2000) Diagnostic and Statistical Manual of Mental Disorders (4th ed., text rev). American Psychiatric Association, Washington, DC.

[16] American Psychiatric Association (2013) Diagnostic and Statistical Manual of Mental Disorders (5th ed.). American Psychiatric Association, Washington, DC.

[17] McKhann GM, Drachman D, Folstein M, Katzman R, Price D, Stadlan EM (1984) Clinical diagnosis of Alzheimer's disease: Report of the NINCDS-ADRDA Work Group under the auspices of Department of Health and Human Services Task Force on Alzheimer's Disease. Neurology 34, 939-944.

[18] McKhann GM, Knopman DS, Chertkow H, Hyman BT, Jack CR Jr, Kawas CH, Klunk WE, Koroshetz WJ, Manly JJ, Mayeux R, Mohs RC, Morris JC, Rossor MN, Scheltens P, Carrillo MC, Thies B, Weintraub S, Phelps $\mathrm{CH}$ (2011) The diagnosis of dementia due to Alzheimer's disease: Recommendations from the National Institute on Aging-Alzheimer's Association workgroups on diagnostic guidelines for Alzheimer's disease. Alzheimers Dement 7, 263-269.

[19] Roman GC, Tatemichi TK, Erkinjuntti T, Cummings JL, Masdeu JC, Garcia JH, Amaducci L, Orgogozo JM, Brun A, Hofman A, Moody DM, O'Brien MD, Yamaguchi T, Grafman J, Drayer BP, Bennett DA, Fisher M, Ogata J, Kokmen E, Bermejo F, Wolf PA, Gorelick PB, Bick KL, Pajeau AK, Bell MA, DeCarli C, Culebras A, Korczyn AD, Bogousslavsky J, Hartmann A, Scheinberg P (1993) Vascular dementia: Diagnostic criteria for research studies: Report of the NINDS-AIREN International Workshop. Neurology 43, 250-260.

[20] Neary D, Snowden JS, Gustafson L, Passant U, Stuss D, Black S, Freedman M, Kertesz A, Robert PH, Albert M,
Boone K, Miller BL, Cummings J, Benson DF (1998) Frontotemporal lobar degeneration. Neurology 51, 1546-1554.

[21] McKeith IG, Dickson DW, Lowe J, Emre M, O'Brien JT, Feldman H, Cummings J, Duda JE, Lippa C, Perry EK, Aarsland D, Arai H, Ballard CG, Boeve B, Burn DJ, Costa D, Del Ser T, Dubois B, Galasko D, Gauthier S, Goetz CG, Gomez-Tortosa E, Halliday G, Hansen LA, Hardy J, Iwatsubo T, Kalaria RN, Kaufer D, Kenny RA, Korczyn A, Kosaka K, Lee VM, Lees A, Litvan I, Londos E, Lopez OL, Minoshima S, Mizuno Y, Molina JA, Mukaetova-Ladinska EB, Pasquier F, Perry RH, Schulz JB, Trojanowski JQ, Yamada M, Consortium on DLB (2005) Diagnosis and management of dementia with Lewy bodies Third report of the DLB consortium. Neurology 65, 1863-1872.

[22] Jodelet D (1989) Représentations sociales: Un domaine en expansion. In Les représentations sociales, Jodelet $\mathrm{D}$, ed. Presses Universitaries de France, Paris, pp. 31-61.

[23] Kleinman A (1980) Patients and Healers in the Context of Culture, California University Press, Berkeley.

[24] Montorio I, Izal M, López A, Sánchez M (1998) La Entrevista de Carga del Cuidador. Utilidad y validez del concepto de carga. An Psicol 14, 229-248.

[25] Folstein M, Folstein S, McHugh PR (1975) Mini-Mental State. A practical method for grading the cognitive state of patients for the clinician. Psychiatry Res 12, 189-198.

[26] Blessed G, Tomlinson BE, Roth M (1968) The association between quantitative measures of dementia and of senile change in the cerebral grey matter of elderly subjects. $\mathrm{Br} J$ Psychiatry 114, 797-811.

[27] Linn MW, Linn BS (1982) The rapid disability rating scale2. J Am Geriatr Soc 30, 378-382.

[28] Reisberg B, Ferris SH, de Leon MJ, Crook T (1982) The global deterioration scale for assessment of primary degenerative dementia. Am J Psychiatry 139, 1136-1139.

[29] Rodríguez Gómez OJ, González Gutiérrez JL, Valencia Sánchez C, García Ptacek S, Marcos Dolado A, Manzano Palomo S (2013) La verdadera eficiencia de las Unidades de Memoria. ¿Qué falla? / Alzheimer disease and the delay of its diagnosis. Alzheimer (Barc., Internet) 53, 32-38.

[30] Manubens JM, Martínez-Lage JM, Lacruz F, Muruzabal J, Larumbe R, Guarch C, Urrutia T, Sarrasqueta P, MartínezLage P, Rocca WA (1995) Prevalence of Alzheimer's disease and other dementing disorders in Pamplona, Spain. Neuroepidemiology 14, 155-164.

[31] Calvo-Perxas L, Osuna MT, Gich J, Eligio-Hernandez E, Linares M, Vinas M, Casas I, Turro-Garriga O, LopezPousa S, Garre-Olmo J, En Representación Del Grupo de Estudio Del Registro de Demencias de, Girona (2012) Características clínicas y demográficas de los casos de demencia diagnosticados en la Región Sanitaria de Girona durante el período 2007-2010: Datos del Registro de Demencias de Girona (ReDeGi). Rev Neurol 54, 399-406.

[32] Gascón-Bayarri J, Reñé R, Del Barrio JL, De Pedro-Cuesta J, Ramón JM, Manubens JM, Sánchez C, Hernández M, Estela J, Juncadella M, Rubio FR (2007) Prevalence of dementia subtypes in El Prat de Llobregat, Catalonia, Spain: The PRATICON study. Neuroepidemiology 28, 224-234.

[33] Grupo de trabajo de la Guía de Práctica Clínica sobre la atención integral a las personas con enfermedad de Alzheimer y otras demencias [GPC]. Guía de Práctica Clínica sobre la atención integral a las personas con enfermedad de Alzheimer y otras demencias. Barcelona: Ministerio de Sanidad Política Social e Igualdad, Spain, 2010. http://www.guiasalud.es/GPC/GPC_484_Alzheimer_ AIAQS_compl.pdf, Accessed on February 20, 2017. 